\title{
A GESTÃO DO CONHECIMENTO E SUA UTILIZAÇÃO NO ENVOLVIMENTO DOS FUNCIONÁRIOS PARA A MELHORIA DO PROCESSO DE RECRUTAMENTO E SELEÇÃO EM CONTACT CENTERS
}

\section{KNOWLEDGE MANAGEMENT AND ITS USE FOR EMPLOYEE INVOLVEMENT IN THE IMPROVEMENT OF THE RECRUITING AND SELECTION PROCESS IN CONTACT CENTERS}

\author{
Samuel Ribeiro Tavares ${ }^{1}$; Milton Vieira Júnior ${ }^{2}$ \\ ${ }^{1}$ Universidade Metodista de Piracicaba - UNIMEP - Santa Bárbara d’Oeste - Brasil \\ samueltavares@yahoo.com \\ ${ }^{2}$ Universidade Nove de Julho - UNINOVE - São Paulo - Brasil \\ mvieirajr@ig.com.br
}

\begin{abstract}
Resumo
Este trabalho oferece uma alternativa para os problemas de elevados tempo de capacitação $e$ turnover em contact centers, por meio da proposição e implementação de abordagem baseada na gestão do conhecimento empresarial para envolvimento dos funcionários na melhoria de seu processo de recrutamento e seleção. Em uma pesquisa experimental, intervencionista, com um componente de orientação crítica, estudou-se o caso de um contact center no Rio de Janeiro. À luz dos resultados obtidos, é possível afirmar que a gestão do conhecimento pode ser usada para o envolvimento dos funcionários e melhoria do processo de recrutamento e seleção em contact centers.
\end{abstract}

Palavras-chave: gestão do conhecimento, contact centers, capacitação, turnover, recrutamento e seleção.

\section{Introdução}

Entre as várias ações para unir foco estratégico e capacidade de execução, as empresas lançam mão de centrais de operações de serviço para interação multimídia direta, dinâmica e diferenciada com os consumidores de suas ofertas: os contact centers (BERGEVIN, 2005), que, ao lhes possibilitarem interagir com seus clientes de forma imediata, monitorando, entendendo e (re)agindo em função de suas percepções, são capazes de contribuir para uma melhor gestão do ciclo de vida dos clientes pelas organizações (CURRY, 2000). 
Para tanto, em sua estruturação completa, os contact centers incorporam cinco áreas de atividade, voltadas para a cobertura de todas as etapas do processo de venda, de modo a expandir ao máximo o ciclo de vida dos clientes junto à organização (SHARP, 2003): marketing, relativa a transações de venda, abrangendo informações sobre o produto ou serviço, auxílio aos clientes na decisão quanto à melhor opção e negociação de condições preços; fulfillment, relativa a transações operacionais, abrangendo entrega ou reparo de produtos físicos, (re)disponibilização de serviços aos clientes, e/ou processamento de dados (e.g. pedidos de venda, pesquisas de campo); customer care, relativa a transações de apoio ou suporte aos clientes, abrangendo ações de atendimento para tratamento às suas dúvidas, solicitações ou reclamações referentes a produtos ou serviços; collection, relativa a transações de pagamento pela aquisição e/ou utilização de produtos ou serviços de uma empresa, abrangendo ações de negociação para (re)financiamento de dívidas vencidas; retention, relativa a transações de retenção de clientes que queiram devolver produtos/cancelar serviços, abrangendo ações de negociação que sejam a última linha-de-defesa para manutenção de sua relação com a empresa.

Contudo, de maneira geral, os contact centers não têm cumprido a contento seu papel de, correspondendo à expectativa de seus clientes, colaborar para sua fidelização, garantindo, com ações efetivas, o retorno sobre o investimento das empresas (MADRUGA, 2006): do ponto de vista dos consumidores, o descontentamento está relacionado, fundamentalmente, tanto à forma (em geral, mecânica) como ao conteúdo (freqüentemente, limitado) das interações com a linha-defrente; para as empresas, a insatisfação está na baixa capacidade dos funcionários da linha-de-frente de, com grande deferência no trato com clientes, converter escolhas fundamentadas em decisões oportunas, e de aproveitar as ligações para gerar novos negócios (DIMENSION DATA, 2006).

Embalados por promessas de fornecedores de hard/software e consultorias em gestão de melhor fidelização de clientes e maior autonomia e participação da linha-de-frente, os contact centers investiram tempo e dinheiro em tecnologia da informação e reprojeto do trabalho (HICKEY, 2003), buscando substituir o modelo "linha-de-produção" (funcionários especialistas, executores de tarefas simples e sem poder de decisão), pelo modelo "empowerment" (funcionários universais, executores autônomos de tarefas complexas) (LAWLER, 2001): para os clientes, esta decisão significaria não mais ter que levar qualquer necessidade, desejo ou aspiração "fora do script" a supervisores com real poder de decisão, aspecto sempre associado a tratamento robotizado, distante e irritante; para os funcionários, subestimados, ela poderia significar motivação; para os supervisores, sobrecarregados com ações operacionais, liberação para gerir; para os gerentes, cobrados por desempenho, efetividade; para as empresas, sucesso (BUTLER, 2004).

Contudo, em sua maioria, estas tentativas, que consumiram esforço e capital, provocaram uma "desilusão corporativa, e pura e simples hostilidade a toda a fanfarra gerada por uma 
abordagem estritamente orientada por dados" (MITCHELL, 2001, p. 42), pois esqueceu-se que o objetivo das empresas não seria atingido com a simples construção de um data base, mas pelo desenvolvimento da capacidade de seus colaboradores de adquirir e transferir conhecimento e modificar seus comportamentos (GRÖNROOS, 2004): mesmo reprojetando o trabalho e implantando várias tecnologias, os contact centers ainda enfrentam baixo desempenho - o tempo médio de qualificação de novos funcionários nestas empresas, incluindo Brasil, é 40 dias, considerando sala-de-treinamento e supervisão por funcionário(a) mais antigo(a), e, ainda assim, eles só se tornam plenamente operacionais em período médio de onze meses (DIMENSION DATA, 2008) - e alto turnover - o índice médio anual de rotatividade de funcionários nestas empresas, incluindo Brasil, cresceu aproximadamente 93\% nos últimos 10 anos, aumentando consideravelmente de 14\% para 27\% (DIMENSION DATA, 2008) - devido às baixas autonomia e auto-estima dos funcionários, agravados por má liderança, processos inadequados e treinamento insuficiente (COEN, 2001).

Desde o fim dos anos 80, entretanto, várias outras organizações começavam a perceber que, mais que um componente casual ou inconsciente, o conhecimento empresarial era - e é - um fator crítico de sucesso, capaz de influenciar seus lucros, presentes e futuros (DAVENPORT, 2005); e, ao identificarem e avaliarem o conhecimento empresarial como ativo organizacional, estas empresas começavam a tentar gerenciá-lo por meio de sistemas e processos, dando início ao que tem sido chamado de gestão do conhecimento (NONAKA, 1991): por meio do gerenciamento explícito e sistemático de conhecimentos vitais à organização, e dos processos de criação, coleta, organização, difusão e exploração a eles associados, elas começavam a buscar - e conseguir - gerar maior valor a seus stakeholders (SKYRME, 1999).

Efetivamente capaz de fornecer tanto know-how - capacidade de execução - como knowwhy - foco estratégico - a gestão do conhecimento constituiu uma alternativa viável para promover a capacidade de agir nas operações de serviço (FIGUEIREDO, 2005): estrategicamente, ela tem propiciado um modelo de gestão baseado na aprendizagem organizacional voltada para o aumento do valor da empresa, por meio do desenvolvimento sua capacidade de sentir e reagir efetivamente às mudanças (DAVENPORT; PRUSAK, 1998); taticamente, ela tem possibilitado o acesso dos funcionários a dados e informações que, influenciando seus conhecimentos, habilidades e atitudes, lhes permitem identificar soluções inovadoras que aumentem a eficácia mercadológica da empresa (SKYRME, 1999); operacionalmente, o compartilhamento de dados e informações tem favorecido a integração de pessoas, processos e tecnologia na entrega de soluções personalizadas que equilibram os aspectos quantitativos e qualitativos da eficiência operacional (SVEIBY, 1998).

Nos contact centers, porém, seu capital intelectual é, ainda, geralmente, subestimado, desconhecendo-se os benefícios da aprendizagem organizacional e da gestão do conhecimento num 
projeto de trabalho que, catalisando esforços, gere uma real vantagem competitiva (ANDERSEN, 2001), pois, em geral, estas operações não constituem ambientes que estimulem e utilizem a capacidade de inovação dos funcionários para criarem oportunidades para soluções radicalmente diferentes para velhos e novos problemas (COEN, 2001): com o trabalho mal projetado, a extensa maioria dos envolvidos nas operações de contact center se apresenta como um contingente despreparado, inchado e burocrático, cuja baixa eficiência operacional dificulta a eficácia mercadológica (SPECTOR, 2005).

\section{Objetivos}

Como resultado destas reflexões sobre contact centers (seu papel, estruturação, desafios, tentativas para superá-los e resultados obtidos), gestão do conhecimento (sua estrutura e proposta) e da atual relação entre ambos, vieram à tona quatro idéias: idéia $\mathbf{1}$ - entre os benefícios mais comuns da gestão do conhecimento são citados: o aumento da eficácia mercadológica e eficiência operacional das empresas, por meio da identificação, captura e disseminação do conhecimento desenvolvido por seus colaboradores (SVEIBY, 1998); idéia 2 - embora, ainda inconclusivas, mais e mais evidências empíricas indicam que, em termos globais, operações de serviço que se afastam do modelo gerencial tradicional - i.e. gerentes decidem; funcionários executam - tornam-se mais competitivas (LELAND; BAILEY, 2006; MUDIE; PIRRIE, 2006; ZEITHAML; BITNER, 2003); idéia 3 - dentre vários desafios, duas das grandes dificuldades que se apresentam para os contact centers são os altos tempo de capacitação operacional e turnover de novos funcionários; e idéia 4 ambos os problemas têm em suas origens a baixa efetividade do processo de atração de mão-deobra, i.e. a identificação das pessoas que apresentam as características desejáveis pela empresa dentre aqueles que nela pretendem ingressar (DAWSON, 2003; READ, 2005).

Submetidas a escrutínio, estas considerações deram origem à principal pergunta deste estudo - "A gestão do conhecimento pode ser usada para o envolvimento dos funcionários na melhoria do processo de recrutamento e seleção em contact centers?" - cuja busca pela resposta seria guiada pelos seguintes objetivos intermediários: objetivo intermediário 1 - identificar o nível de desempenho de um contact center em seu processo de recrutamento e seleção antes da aplicação da abordagem proposta no presente estudo; objetivo intermediário 2 - identificar o grau de envolvimento dos funcionários do contact center selecionado em seu processo de recrutamento e seleção antes da aplicação da abordagem proposta no presente estudo; objetivo intermediário 3 identificar o modo de gestão do conhecimento empresarial do contact center selecionado em seu processo de recrutamento e seleção antes da aplicação da abordagem proposta no presente estudo; objetivo intermediário 4 - identificar uma abordagem para melhoria do processo de recrutamento 
e seleção no contact center selecionado utilizando a gestão do conhecimento para o envolvimento dos funcionários; objetivo intermediário 5 - disseminar e garantir a adesão de todos no contact center selecionado à abordagem proposta, por meio da aplicação, monitoração e ajuste das várias ações em seu processo de recrutamento e seleção; objetivo intermediário 6 - verificar o nível de desempenho obtido pelo contact center selecionado em seu processo de recrutamento e seleção depois da aplicação da abordagem proposta no presente estudo; objetivo intermediário 7 identificar o grau de envolvimento dos funcionários do contact center selecionado em seu processo de recrutamento e seleção depois da aplicação da abordagem proposta no presente estudo; objetivo intermediário 8 - identificar a ocorrência de alterações no modo de gestão do conhecimento empresarial no contact center selecionado em seu processo de recrutamento e seleção depois da aplicação da abordagem proposta no presente estudo.

Sendo comprometimento de funcionários e conhecimento empresarial ativos críticos de negócios, cuja gestão envolve riscos e vantagens, seu entendimento e aplicação se colocava (e coloca) entre os principais tópicos de pesquisa em operações (JOHNSTON; CLARK, 2002).

\section{Metodologia}

Este estudo, realizado de 02/2008 a 10/2008, constituiu uma intervenção planejada na realidade do collection de um contact center no Rio de Janeiro, que prestava serviços a empresas do segmento financeiro no ramo de financiamento de bens de consumo: 8 equipes - cada uma composta por 25 funcionários (total 200), ligados a 1 supervisor(a) (total 8), sob a responsabilidade de 1 gerente - que tinham por tarefa negociar dívidas vencidas, representaram, ao mesmo tempo, o universo e a amostra da pesquisa.

Quanto aos fins, ao estudar a influência de uma abordagem com base na gestão do conhecimento para envolvimento dos funcionários para melhoria do desempenho organizacional, esta foi uma pesquisa experimental (GIL, 1996); quanto aos meios, ao interferir para modificar a realidade estudada, não só propondo uma resolução para seus problemas, mas tentando resolvê-los de maneira efetiva e participativa, este estudo constituiu uma investigação intervencionista (VERGARA, 1998); quanto ao posicionamento frente ao conhecimento, ao encarar o desempenho empresarial como um imperativo em torno do qual todo conhecimento ou prática deve ser gerado, este trabalho apresentou, stricto sensu, uma orientação não crítica (DAVEL; ALCADIPANI, 2003), contudo, ao, explicitamente, indicar que as pessoas que constituem as organizações devem aprender permanentemente umas com as outras, com seus clientes, fornecedores e mercados, este estudo trouxe em si um componente crítico (VERGARA; BRANCO, 2001), na medida em que não só admitiu a possibilidade, como buscou contribuir para estimular o desenvolvimento de modelos 
gerenciais que tragam menos dominação e exclusão, rejeitando ações opressivas, percebidas como inúteis nas empresas no mundo contemporâneo.

Como método de abordagem, este estudo utilizou o método hipotético-dedutivo, que, ao perceber lacunas de conhecimento, gera hipóteses e, por inferência dedutiva, testa a predição da ocorrência de fenômenos/fatos por elas abrangidos (POPPER, 1975a, 1975b); como método de procedimento, ele se embasou no estruturalismo, que analisa um acontecimento concreto, gera um modelo abstrato que retrata o objeto estudado, e volta ao concreto, numa realidade estruturada da experiência dos sujeitos sociais (KAUFMANN, 1977); como método de investigação, ele lançou mão da pesquisa-ação, no qual pesquisadores e sujeitos representativos do problema decidem, empiricamente, envolver-se de modo cooperativo/participativo na tentativa de resolver um problema (THIOLLENT, 1997).

Dentre as técnicas de coleta de dados, este estudo utilizou pesquisa documental, observação participante, entrevistas (estruturadas e não-estruturadas não-dirigidas) e questionários (perguntas abertas, fechadas e de estimação com escala Lickert) (MARCONI; LAKATOS, 1990); e, dentre as técnicas de análise de dados, este estudo utilizou tanto a abordagem de tratamento quantitativo, como a abordagem de tratamento qualitativo (MARCONI; LAKATOS, 1990).

\section{Desenvolvimento}

Encarando pesquisas científicas como decorrentes da identificação de dúvidas e da necessidade de elaboração e construção de respostas para esclarecê-las, estes pesquisadores, apoiados no método hipotético-dedutivo, desenvolveram as hipóteses H1 "a gestão do conhecimento contribui para o envolvimento de funcionários" e H2 "o envolvimento de funcionários pode melhorar o processo de recrutamento e seleção".

Acreditando que os elementos de um dado sistema não são explicativos em e por si mesmos, mas participantes de relações com o todo, maior que a mera soma das partes, estes pesquisadores usaram o método estruturalista no desenvolvimento de seu arcabouço teórico (Figura 1): neste modelo, ações para gestão do conhecimento empresarial referente a recrutamento e seleção envolveriam os atuais funcionários, cujas experiências, percepções e idéias seriam mapeadas e aproveitadas para melhoria nível de desempenho do collection. 
Figura 1 - Arcabouço teórico

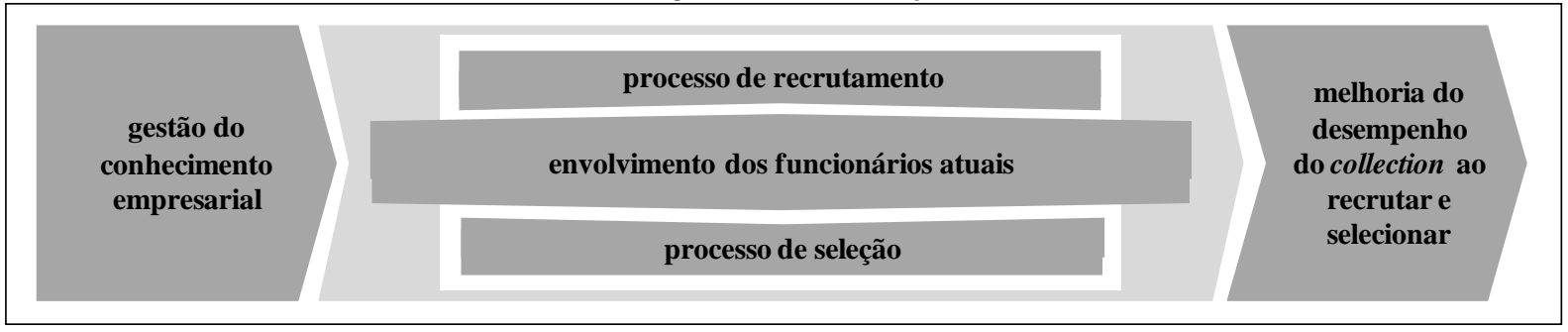

Fonte: Desenvolvido pelos autores

Confiando no potencial dos sujeitos da pesquisa para colaborarem tanto na identificação de aspectos prioritários, como na implantação e avaliação de ações, estes pesquisadores adotaram o método pesquisa-ação (vide 3): 8 funcionários e 3 supervisores - identificados pela própria empresa, que os viam como participantes-chave deste estudo, capazes de atuar em grupo, lidar com incertezas e mudanças, e com conhecimentos/habilidades técnico-comportamentais que garantissem a execução do projeto - não só validaram o arcabouço teórico idealizado, como também, concordando com os objetivos intermediários definidos por estes pesquisadores para a execução deste estudo, colaboraram na elaboração do cronograma de trabalho (Figura 2).

Figura 2 - Cronograma de trabalho

\begin{tabular}{|c|c|c|}
\hline $\begin{array}{l}\qquad 04 / 02 / 08-08 / 02 / 08 \\
\text { identificar o nível de } \\
\text { desempenho do processo } \\
\text { de recrutamento } \\
\text { e seleção }\end{array}$ & $04 / 02 / 08-29 / 02 / 08$ & $\begin{array}{r}06 / 10 / 08-10 / 10 / 08 \\
\text { identificar o nível de } \\
\text { desempenho do processo } \\
\text { de recrutamento } \\
\text { e seleção }\end{array}$ \\
\hline $\begin{array}{l}\qquad 11 / 02 / 08-15 / 02 / 08 \\
\text { identificar o grau de } \\
\text { envolvimento dos } \\
\text { funcionários com } \\
\text { recrutamento e seleção }\end{array}$ & $\begin{array}{l}\text { identificar abordagem } \\
\text { baseada na gestão } \\
\text { do conhecimento } \\
\quad \text { garantir a adesão } \\
\text { g̀ aho }\end{array}$ & $\begin{array}{r}\text { 13/10/08 - 17/10/08 } \\
\text { identificar o grau de } \\
\text { envolvimento dos } \\
\text { funcionários com } \\
\text { recrutamento e seleção }\end{array}$ \\
\hline $\begin{array}{l}\qquad 18 / 02 / 08-22 / 02 / 08 \\
\text { identificar o modo de } \\
\text { gestão do conhecimento no } \\
\text { processo de recrutamento } \\
\text { e seleção }\end{array}$ & $03 / 03 / 08-03 / 10 / 08$ & $\begin{array}{r}20 / 10 / 08-24 / 10 / 08 \\
\text { identificar o modo de } \\
\text { gestão do conhecimento no } \\
\text { processo de recrutamento } \\
\text { e seleção }\end{array}$ \\
\hline
\end{tabular}

Fonte: Desenvolvido pelos autores

\subsection{Nível de desempenho antes da aplicação da abordagem proposta}

Em linha com o método pesquisa-ação, estes pesquisadores, junto com os participanteschave deste estudo, definiram "tempo de capacitação" e "turnover mensal" como indicadores relevantes do nível de desempenho do collection em seu processo de recrutamento e seleção: o indicador tempo de capacitação foi obtido por meio da análise do tempo para que os funcionários atingissem o desempenho mínimo esperado pelo collection (70\% das negociações de dívidas vencidas/a vencerem concretizadas em pagamentos pelos clientes); o indicador turnover mensal foi 
obtido por meio da análise da relação existente entre o número de funcionários que se desligaram e o número total de funcionários do collection em cada mês

Seu uso (04/02/08-08/02/08) para identificar o nível médio de desempenho do collection em seu processo de recrutamento e seleção antes da aplicação da abordagem proposta neste estudo (Figura 3) revelou tempo de capacitação de 8 meses e turnover mensal de $11 \%$.

Figura 3 - Nível de desempenho antes da aplicação da abordagem proposta

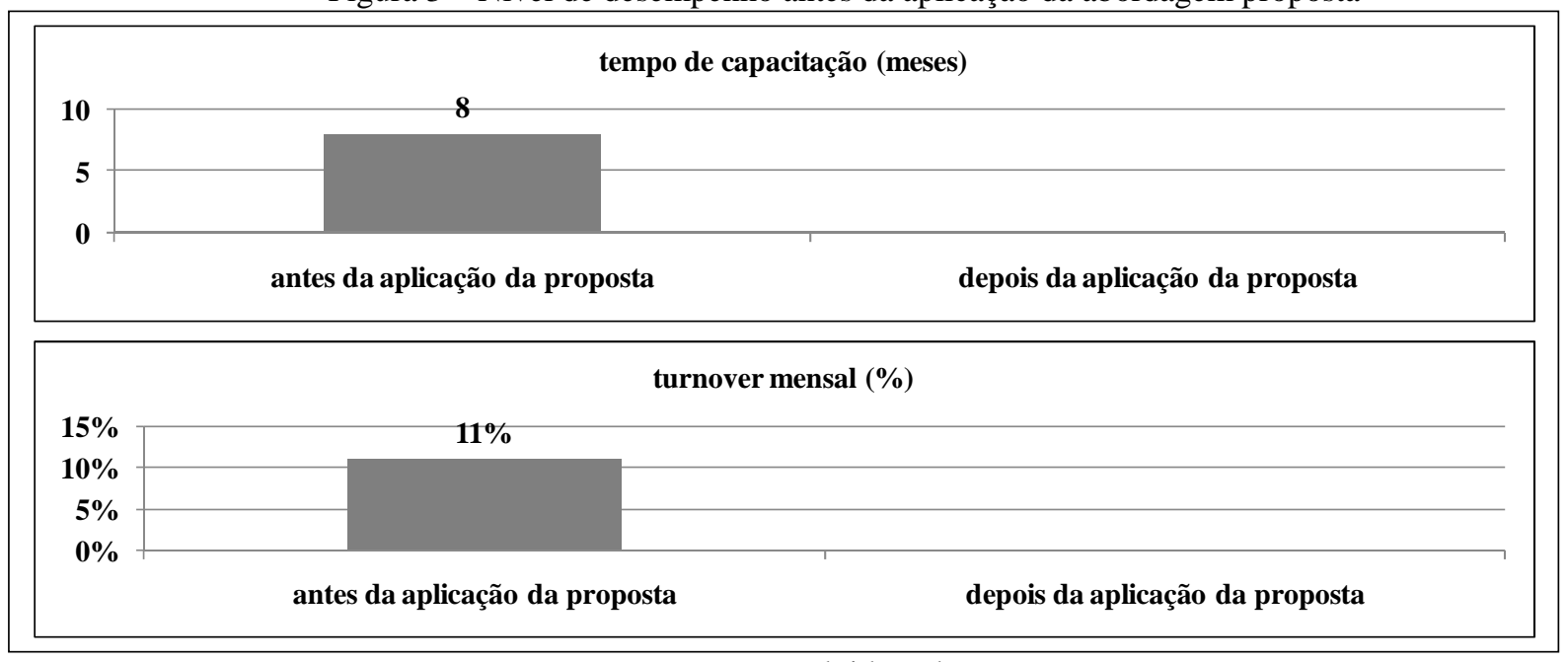

Fonte: Desenvolvido pelos autores

\subsection{Grau de envolvimento dos funcionários antes da aplicação da abordagem proposta}

Para identificar o grau de envolvimento dos funcionários com o processo de recrutamento e seleção do collection antes da aplicação da abordagem proposta neste estudo, pesquisadores e participantes-chave, conforme o método pesquisa-ação, criaram um questionário fechado. Este instrumento contemplou os quatro tipos básicos de participação de funcionários no processo de recrutamento e seleção em uma organização (BOHLANDER et al., 2003; CHIAVENATO, 2004): na indicação de candidatos; na elaboração dos parâmetros de seleção; na elaboração e/ou na aplicação dos testes de seleção.

De 11/02/08 a 15/02/08, os funcionários, após explicações dos participantes-chave nas reuniões semanais das equipes, responderam um formulário eletrônico, que revelou (Figura 4) baixa participação (96\%) e baixa satisfação (95\%) com o processo de recrutamento e seleção no collection. 
Figura 4 - Grau de envolvimento dos funcionários antes da aplicação da abordagem proposta

\begin{tabular}{|c|c|c|c|c|c|c|}
\hline \multirow{2}{*}{$\begin{array}{c}\text { processo de recrutamento e seleção no collection } \\
\text { antes da aplicação da proposta }\end{array}$} & \multicolumn{3}{|c|}{ grau de participação } & \multicolumn{3}{|c|}{ grau de satisfação } \\
\hline & baixa & média & alta & baixa & média & alta \\
\hline indicação de novos funcionários & $90 \%$ & $8 \%$ & $2 \%$ & $\mathbf{8 8 \%}$ & $10 \%$ & $2 \%$ \\
\hline elaboração de parâmetros para seleção de novos funcionários & 98\% & $2 \%$ & $\mathbf{0 \%}$ & $97 \%$ & $2 \%$ & $1 \%$ \\
\hline elaboração de testes para seleção de novos funcionários & 99\% & $1 \%$ & $\mathbf{0 \%}$ & $\mathbf{9 8 \%}$ & $1 \%$ & $1 \%$ \\
\hline aplicação de testes para seleção de novos funcionários & $97 \%$ & $1 \%$ & $2 \%$ & $96 \%$ & $3 \%$ & $1 \%$ \\
\hline média & $96 \%$ & $3 \%$ & $1 \%$ & $95 \%$ & $4 \%$ & $1 \%$ \\
\hline
\end{tabular}

Fonte: Adaptado de Bohlander et al.(2003) e Chiavenato ( 2004)

\subsection{Modo de gestão do conhecimento antes da aplicação da abordagem proposta}

Para identificar como o collection geria seu conhecimento empresarial no processo de recrutamento e seleção antes da aplicação da abordagem proposta neste estudo, pesquisadores e participantes-chave, conforme o método pesquisa-ação, criaram novo questionário fechado. Este instrumento contemplou as três decisões fundamentais que servem como referencial para as ações estruturadas de gestão do conhecimento empresarial em uma organização - geração, partilha e uso (MORESI, 2001): decisão 1 - gerar conhecimento empresarial diz respeito à formulação de uma política estratégica que possibilite o desenvolvimento e aplicação do conhecimento na organização como um todo; decisão $\mathbf{2}$ - partilhar conhecimento empresarial se refere à definição e implementação de estratégias organizacionais para a reunião e disponibilização do conhecimento de cada empresa; decisão 3 - usar conhecimento empresarial se relaciona com o acompanhamento da melhoria diária da organização em função do uso e o desenvolvimento do conhecimento frente aos objetivos propostos.

De 18/02/08 a 22/02/08, os funcionários, após explicações dos participantes-chave nas reuniões semanais das equipes, responderam um formulário eletrônico, que revelou (Figura 5) crença média de $21 \%$ na existência de um modo estruturado de gerir o conhecimento no collection.

Figura 5 - Modo de gestão do conhecimento antes da aplicação da abordagem proposta

\begin{tabular}{|c|c|c|c|}
\hline \multicolumn{2}{|r|}{ gestão do conhecimento sobre recrutamento e seleção antes da aplicação da abordagem proposta } & \multirow{2}{*}{\begin{tabular}{|c|} 
sim \\
$13 \%$ \\
\end{tabular}} & \multirow{2}{*}{\begin{tabular}{|c} 
não \\
$87 \%$ \\
\end{tabular}} \\
\hline $\bar{\pi}$ & o collection identifica e armazenar o conhecimento organizacional em bancos de dados & & \\
\hline 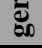 & o collection compartilha o conhecimento organizacional por meio de contatos pessoais & $23 \%$ & $77 \%$ \\
\hline \multirow{3}{*}{ 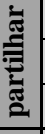 } & o collection utiliza tecnologia com o objetivo de fazer mais e melhor do que já se fazia & $35 \%$ & $65 \%$ \\
\hline & o collection utiliza processos com o objetivo de promover a inovação e a criatividade & $28 \%$ & $72 \%$ \\
\hline & o collection utiliza diversas disciplinas com o objetivo de obter resultados sustentáveis & $21 \%$ & $79 \%$ \\
\hline \multirow{4}{*}{ 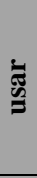 } & o collection explicita estratégias, indicadores de desempenho e planos de ação & $11 \%$ & $89 \%$ \\
\hline & o collection organiza e disponibiliza informações existentes dentro e fora organização & $11 \%$ & $89 \%$ \\
\hline & o collection identifica, forma, mantém e atualiza as competências das pessoas & $30 \%$ & 70\% \\
\hline & o collection otimiza a tecnologia da informação com investimentos diretos e substanciais & $20 \%$ & $80 \%$ \\
\hline & média geral & $21 \%$ & $79 \%$ \\
\hline
\end{tabular}

Fonte: Adaptado de Moresi (2001) 


\subsection{Abordagem para melhoria do processo de recrutamento e seleção no collection}

Na elaboração de uma abordagem para melhoria do processo de recrutamento e seleção no collection utilizando a gestão do conhecimento para o envolvimento dos funcionários, estes pesquisadores trabalharam com dois conceitos fundamentais: conceito 1 - há atividades básicas comuns a todo processo de gestão do conhecimento empresarial; conceito 2 - o envolvimento de funcionários em qualquer proposta nas empresas passa pela definição (e execução) de um adequado modelo de gestão de mudanças.

\subsubsection{Gestão do conhecimento - atividades básicas}

Embora não exista uma abordagem única para a gestão do conhecimento capaz de atender a todas as empresas em suas necessidades específicas, existem nove atividades básicas presentes em qualquer intervenção nesta área (PROBST et al., 2002): atividade 1 - a condição fundamental para o sucesso das ações de gestão do conhecimento é o reconhecimento consciente e formal pela empresa do papel do conhecimento na Era da Informação, e da necessidade de gerirem seus ativos intelectuais; atividade $\mathbf{2}$ - a partir daí, a segunda atividade é a definição das metas de conhecimento, i.e. a definição dos objetivos para ações de gestão do conhecimento visando alinhálos aos objetivos da empresa; atividade 3 - a terceira atividade é a identificação do conhecimento, i.e. a análise e descrição do ambiente de conhecimento da empresa, visando à escolha dos tipos de conhecimento que contribuem para a competitividade organizacional; atividade 4 - a quarta atividade é aquisição de conhecimento, i.e. a importação do conhecimento de fontes externas às empresas, visando eliminar a síndrome do não foi inventado aqui e a falsa sensação de segurança que confere às organizações; atividade 5 - a quinta atividade é o desenvolvimento do conhecimento, i.e. o empenho da empresa por adquirir as competências que não tem ou que ainda não existem, visando à geração de novas e melhores habilidades, produtos, idéias e processos; atividade 6 - a sexta atividade é o compartilhamento do conhecimento, i.e. a distribuição e disseminação do conhecimento organizacional, visando disponibilizar informações e experiências que contribuam para tomada de decisões efetivas em todos os níveis; atividade 7 - a sétima atividade é a aplicação do conhecimento, i.e. o encorajamento ao abandono das rotinas conhecidas nas tarefas diárias e o estímulo à incerteza e ao desconhecido, visando à utilização produtiva do conhecimento organizacional; atividade 8 - a oitava atividade é a retenção do conhecimento, i.e. a seleção, armazenamento e atualização regulares de conhecimento vital à organização no presente ou futuro, visando à preservação de sua memória, referência para novas experiências; atividade 9 - a nona atividade é a avaliação do conhecimento, i.e. a identificação de índices significativos do 
estado da base de conhecimento empresarial, visando à decisão quanto ao alcance ou não dos objetivos de conhecimento.

\subsubsection{Gestão de mudanças - definição de um modelo adequado}

Qualquer ação que busque instituir novas idéias e atitudes nas empresas deve ser seriamente encarada como uma mudança organizacional, que precisa ser adequadamente gerida para que se obtenham os resultados desejados (PORTNY, 2001); e, dentre as abordagens à gestão da mudança, destaca-se um modelo afinado com a gestão do conhecimento organizacional, com etapas interdependentes, focado em resultados, apoiado na conscientização dos funcionários e no desenvolvimento do conhecimento empresarial (FISCHER, 2002): a etapa de investigação visa obter e analisar dados que identifiquem as especificidades dos processos de trabalho, fluxos de comunicação e interação entre as diferentes áreas organizacionais, que impactem na implementação do modelo proposto; a etapa de concepção representa a transição entre a constatação de dificuldades e oportunidades e a implementação do modelo proposto e a construção interativa de um modo exeqüível de conceber e guiar a mudança pelos participantes-chave; a etapa de disseminação contrapõe as propostas geradas na etapa de concepção às necessidades da organização e expectativas dos demais funcionários, demandando decisões próximas da ação, decisão consensual e comunicação em mão dupla; e a etapa de sustentação tem por objetivo acompanhar de modo ativo o processo de implementação do modelo proposto, envolvendo observação, análise e eventuais ajustes nas ações planejadas e adotadas.

\subsubsection{Abordagem proposta - gestão do conhecimento para envolvimento de funcionários}

Apoiados nestes conceitos, e guiados pelos métodos hipotético-dedutivo e estruturalista, estes pesquisadores, 04/02/08 a 29/02/08, criaram abordagem para melhoria do recrutamento e seleção no collection, validado pelos participantes-chave, seguindo o método pesquisa-ação. Nela (Figura 6), a partir do reconhecimento do papel do conhecimento, as atividades básicas na gestão do conhecimento (vide 4.4.1), constituiriam as etapas de investigação, concepção, disseminação e sustentação da mudança (vide 4.4.2), abrangendo o que, por que e como mudar, e com que resultados. 
Figura 6 - Modelo para disseminação e garantia de adesão à abordagem proposta

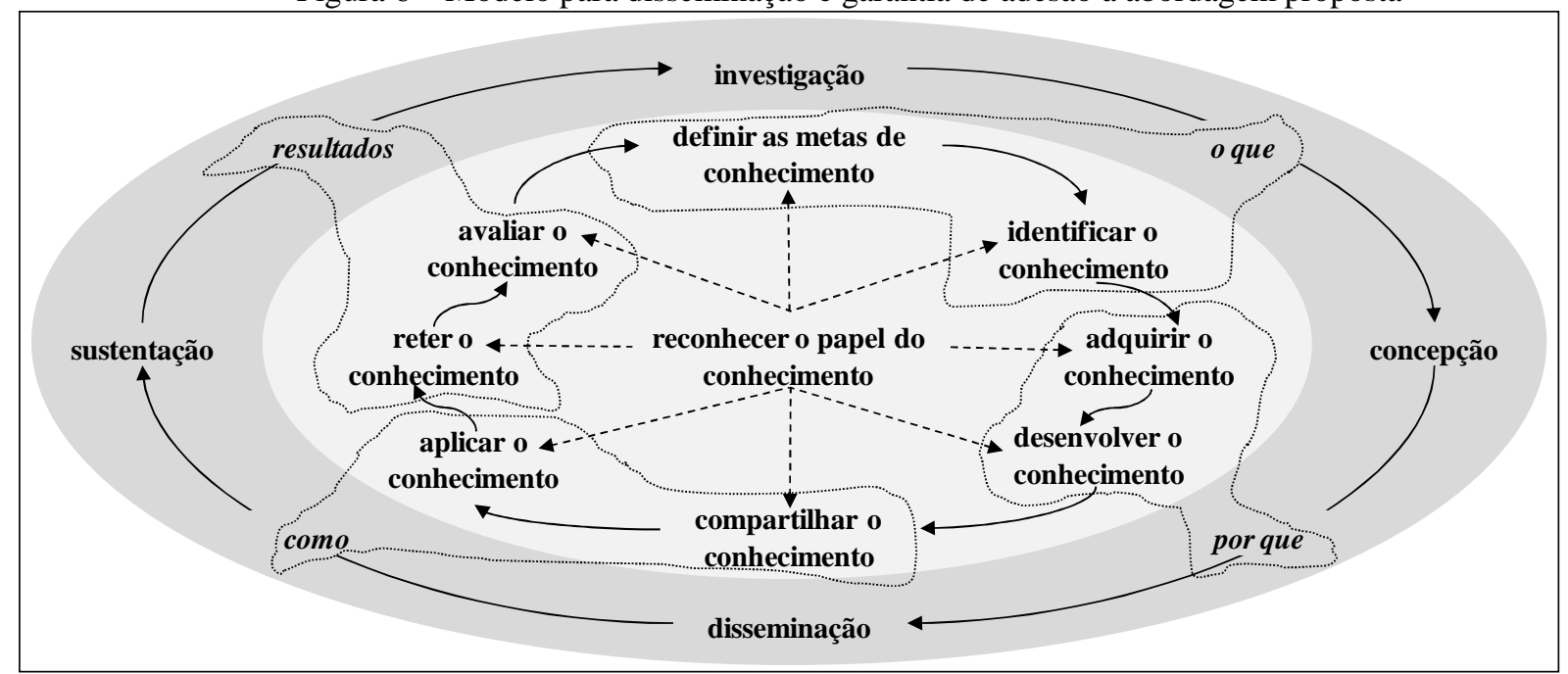

Fonte: Adaptado de Probst et al. (2002) e Fischer (2002)

\subsection{Disseminação e garantia de adesão à abordagem proposta}

$\mathrm{Na}$ concretização da abordagem proposta, de 03/03/08 a 03/10/08, pesquisadores e participantes-chave, conforme o método pesquisa-ação, definiram, implantaram, monitoraram e ajustaram um conjunto de ações (Figura 7) para obtenção da contribuição dos funcionários. 
Figura 7 - Abordagem baseada na gestão do conhecimento

\begin{tabular}{|c|c|}
\hline \multicolumn{2}{|c|}{ abordagem baseada na gestão do conhecimento para o processo de recrutamento e seleção } \\
\hline atividades de gestão do conhecimento & ações propostas \\
\hline reconhecer o papel do conhecimento & $\begin{array}{l}\text { campanha para estimular contribuições dos funcionários para o processo de } \\
\text { recrutamento e seleção - campanha se apoiou em comunicação (reuniões, } \\
\text { murais e intranet), treinamento e coaching }\end{array}$ \\
\hline definir as metas de conhecimento & $\begin{array}{l}\text { solicitação de contribuições dos funcionários voltadas à redução do turnover e } \\
\text { do tempo de qualificação de funcionários - direcionamento das contribuiçães } \\
\text { dos funcionários tornava sua participação mais tangível }\end{array}$ \\
\hline identificar o conhecimento & $\begin{array}{l}\text { idéias/sugestões relativas a funcionários (perfil ideal), processos e tecnologia } \\
\text { no recrutamento e seleção - buscava-se mostrar o desejo genuíno por } \\
\text { idéias/sugestões baseadas nas experiências e crenças dos funcionários }\end{array}$ \\
\hline adquirir o conhecimento & $\begin{array}{l}\text { uso da intranet, reuniões semanais, entrevistas com supervisores, e conversas } \\
\text { com participantes-chave na interação com funcionários - objetivo era criar } \\
\text { clima e mecanismos para obtenção de toda e qualquer idéia/sugestão }\end{array}$ \\
\hline desenvolver o conhecimento & $\begin{array}{l}\text { workshops com funcionários e gestores do collection para brainstorming e } \\
\text { validação das idéias/sugestões apresentadas - workshops fora do horário de } \\
\text { trabalho e com remuneração extra: investimento e justiça }\end{array}$ \\
\hline compartilhar o conhecimento & $\begin{array}{l}\text { workshops com Recursos Humanos para brainstorming das idéias/sugestões } \\
\text { validadas nos workshops realizados no collection - Recursos Humanos, } \\
\text { envolvido desde o início da pesquisa, mostrou-se confortável todo o tempo }\end{array}$ \\
\hline aplicar o conhecimento & $\begin{array}{l}\text { inclusão das idéias/sugestões validadas nos workshops com Recursos Humanos } \\
\text { nas atividades de recrutamento e seleção - as idéias/sugestões abrangeram } \\
\text { otimização e reinvenção das atividades do processo de recrutamento e seleção }\end{array}$ \\
\hline reter o conhecimento & $\begin{array}{l}\text { registro das idéias/sugestões validadas nos workshops com Recursos Humanos } \\
\text { no manual de recrutamento e seleção - alocação na intranet e inclusão em } \\
\text { treinamentos (qualificação/reciclagem) para estímulo à participação de todos }\end{array}$ \\
\hline avaliar o conhecimento & $\begin{array}{l}\text { acompanhamento mais de perto dos novos funcionários pelos supervisores no } \\
\text { período de experiência - coaching dos novos funcionários pelos supervisores, } \\
\text { comfeedback (quantitativo e qualitativo) a Recursos Humanos }\end{array}$ \\
\hline
\end{tabular}

Fonte: Adaptado de Probst et al. (2002)

Embora autorizasse a realização deste estudo e a descrição do contexto, ações adotadas e resultados obtidos com a aplicação desta abordagem, o collection não permitiu a divulgação do conteúdo das contribuições dos funcionários adotadas por sua área de Recursos Humanos.

\subsection{Nível de desempenho depois da aplicação da abordagem proposta}

A identificação, de 06/10/08 a 10/10/08, do nível médio de desempenho do collection em seu processo de recrutamento e seleção depois da aplicação da abordagem proposta neste estudo (Figura 8) revelou tempo de capacitação de 4 meses e turnover mensal de 3\%. 
Figura 8 - Nível de desempenho depois da aplicação da abordagem proposta

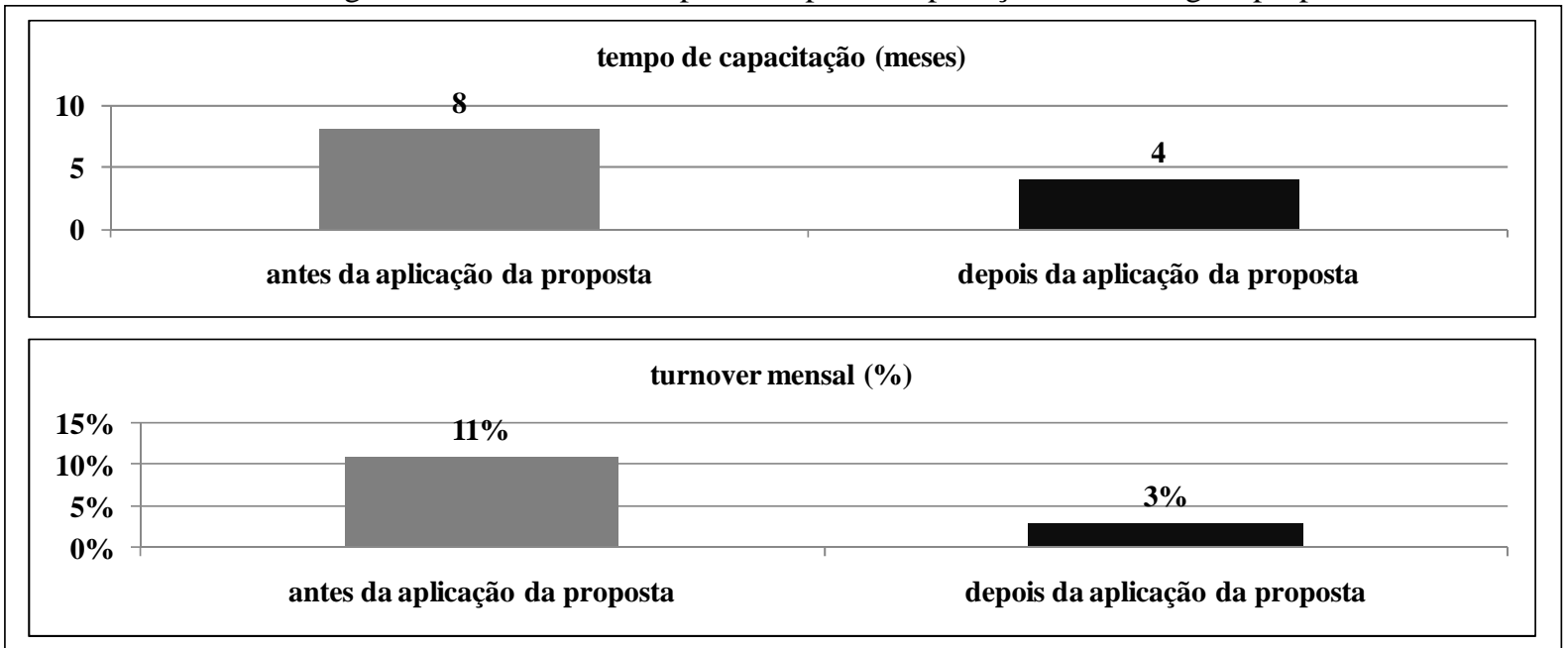

Fonte: Desenvolvido pelos autores

Com relação ao turnover, foram considerados os funcionários contratados após o início deste estudo que se desligaram do collection e o número total de novos funcionários contratados após o início deste estudo e, embora a amostragem fosse de apenas 6 meses (contratações entre 03/03/08 e 03/10/08), ela foi considerada relevante pela empresa, que informou que seu maior volume de desligamentos ocorre no período de até 3 meses após as contratações.

\subsection{Grau de envolvimento dos funcionários depois da aplicação da abordagem proposta}

De 13/10/08 a 17/10/08, os funcionários refizeram o questionário eletrônico (vide 4.2), revelando em média (Figura 9) 94\% de participação e 92\% de satisfação com o processo de recrutamento e seleção no collection, depois da aplicação da abordagem proposta neste estudo.

Figura 9 - Grau de envolvimento dos funcionários depois aplicação da abordagem proposta

\begin{tabular}{|c|c|c|c|c|c|c|}
\hline \multirow{2}{*}{$\begin{array}{l}\text { processo de recrutamento e seleção no collection } \\
\text { depois da aplicação da proposta }\end{array}$} & \multicolumn{3}{|c|}{ grau de participação } & \multicolumn{3}{|c|}{ grau de satisfação } \\
\hline & baixa & média & alta & baixa & média & alta \\
\hline indicação de novos funcionários & $2 \%$ & $6 \%$ & $92 \%$ & $3 \%$ & $7 \%$ & $90 \%$ \\
\hline elaboração de parâmetros para seleção de novos funcionários & $1 \%$ & $4 \%$ & $95 \%$ & $2 \%$ & $8 \%$ & $90 \%$ \\
\hline elaboração de testes para seleção de novos funcionários & $1 \%$ & $4 \%$ & $95 \%$ & $2 \%$ & $5 \%$ & 93\% \\
\hline aplicação de testes para seleção de novos funcionários & $2 \%$ & $3 \%$ & $95 \%$ & $1 \%$ & $4 \%$ & $95 \%$ \\
\hline média & $2 \%$ & $4 \%$ & $94 \%$ & $2 \%$ & $6 \%$ & $92 \%$ \\
\hline
\end{tabular}

Fonte: Adaptado de Bohlander et al.(2003) e Chiavenato ( 2004)

\subsection{Modo de gestão do conhecimento depois da aplicação da abordagem proposta}

De 20/10/08 a 24/10/08, os funcionários voltaram a responder o questionário eletrônico (vide 4.3), revelando (Figura 10) crença média de $76 \%$ na existência de um modo estruturado de gerir o conhecimento no collection. 
Figura 10 - Modo de gestão do conhecimento depois da aplicação da abordagem proposta

\begin{tabular}{|c|c|c|c|}
\hline \multicolumn{2}{|r|}{ ações de gestão do conhecimento no collection depois da aplicação da proposta } & sim & não \\
\hline \multirow{2}{*}{ 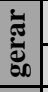 } & o collection identifica e armazenar o conhecimento organizacional em bancos de dados & $85 \%$ & $15 \%$ \\
\hline & o collection compartilha o conhecimento organizacional por meio de contatos pessoais & $82 \%$ & $18 \%$ \\
\hline \multirow{3}{*}{ 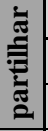 } & o collection utiliza tecnologia com o objetivo de fazer mais e melhor do que já se fazia & $73 \%$ & $27 \%$ \\
\hline & o collection utiliza processos com o objetivo de promover a inovação e a criatividade & $70 \%$ & $30 \%$ \\
\hline & o collection utiliza diversas disciplinas com o objetivo de obter resultados sustentáveis & $74 \%$ & $26 \%$ \\
\hline \multirow{4}{*}{ 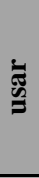 } & o collection explicita estratégias, indicadores de desempenho e planos de ação & $76 \%$ & $24 \%$ \\
\hline & o collection organiza e disponibiliza informações existentes dentro e fora organização & $79 \%$ & $21 \%$ \\
\hline & o collection identifica, forma, mantém e atualiza as competências das pessoas & $78 \%$ & $22 \%$ \\
\hline & o collection otimiza a tecnologia da informação com investimentos diretos e substanciais & $69 \%$ & $31 \%$ \\
\hline & média geral & $76 \%$ & $24 \%$ \\
\hline
\end{tabular}

Fonte: Adaptado de Moresi (2001)

\section{Resultados}

Quando considerado que os funcionários perceberam a ocorrência de uma alteração no modo de gestão do conhecimento empresarial no processo de recrutamento e seleção do collection, podese inferir que a abordagem proposta no presente estudo foi implementada.

Quando considerado que houve aumento na percepção de participação e satisfação dos funcionários com o processo de recrutamento e seleção do collection, pode-se inferir que a abordagem proposta no presente estudo contribuiu para o aumento de seu envolvimento.

Quando considerado que o nível de desempenho do collection em seu processo de recrutamento e seleção melhorou, pode-se inferir que a abordagem proposta no presente estudo contribuiu para sua melhoria.

Assim, à luz dos resultados obtidos neste trabalho, é possível afirmar, sem, contudo, qualquer pretensão de generalização, que ambas as hipóteses deste estudo - H1 "a gestão do conhecimento contribui para o envolvimento de funcionários" e H2 "o envolvimento de funcionários pode melhorar o processo de recrutamento e seleção" - eram "verdadeiras"; e que a resposta para a pergunta de pesquisa é "Sim, a gestão do conhecimento pode ser usada para o envolvimento dos funcionários na melhoria do processo de recrutamento e seleção em contact centers".

\section{Considerações finais}

Os contact centers vêm se desenvolvendo em ritmo incrivelmente forte, ocupando, hoje, o segundo lugar no ranking de empregadores privados no Brasil (DAMASCENO, 2005) e contribuindo com $7 \%$ do total dos postos de trabalho oferecidos em todo o mundo (BERGEVIN, 
2005); apesar disso, na realização deste trabalho, observou-se limitada existência de estudos científicos e amplos desafios enfrentados por empresários, gestores e funcionários no setor, indicando a necessidade/oportunidade de maior atenção por parte da comunidade acadêmica.

\begin{abstract}
This paper offers an alternative to the problems of long training periods and high turnover in contact centers, through the proposition and implementation of an approach based on knowledge management for employee involvement in the improvement of the recruiting and selection process. In an experimental, interventionist (although with a critical orientation flavor) research, the case of a contact center in Rio de Janeiro was studied. In light of the achieved results, it is possible to say that knowledge management can be successfully used for employee involvement in the improvement of the recruiting and selection process in contact centers.
\end{abstract}

Key-words: knowledge management; contact centers; training; turnover; hiring.

\title{
Referências
}

BERGEVIN, R. Call Centers for Dummies. Ontario: Wiley, 2005.

BOHLANDER, G.; SNELL, S.; SHERMAN, A. Administração de RH. São Paulo: Thompson, 2003.

BUTLER, D. L. Bottom-Line Call Center Management. Burlington: Butterworth-Heineman, 2004.

CHIAVEnATO, I. Gestão de Pessoas. Rio de Janeiro: Campus, 2004.

COEN, D. Building Call Center Culture. Tarzana: DCD Publishing, 2001.

CURRY, J. The Customer Marketing Method. New York: The Free Press, 2000.

DAMASCENO, S. Todas as Posições Ocupadas: Até Logo. Teletime, São Paulo, maio, 2005.

DAVEL, E.; ALCADIPANI, R. Estudos Críticos em Administração. RAE, São Paulo, v. 43, 2003.

DAVENPORT, T. H. Thinking for a Living. Boston: Harvard Business School Press, 2005.

DAVENPORT, T. H.; PRUSAK, L. Working Knowledge. Boston: Harvard Business School Press, 1998.

DAWSON, K. The Call Center Handbook. Gilroy: CMP Books, 2003.

DIMENSION DATA. The Global Benchmarking Report 2006. Disponível em: <http://www.dimensiondata.com>. Acesso em: 30 abr. 2007.

DIMENSION DATA. Call Center Benchmark Report 2008. Disponível em: <http://www.dimensiondata.com>. Acesso em: 06 jul. 2008.

FIGUEIREDO, S. P. Gestão do Conhecimento. Rio de Janeiro: Qualitymark, 2005.

FISCHER, R. M. Mudança e Transformação Organizacional. In: FLEURY, M. T. L. (Org.) As Pessoas na Organização. São Paulo: Gente. 2002.

GIL, A. A. C. Como Elaborar Projetos de Pesquisa. São Paulo: Atlas, 1996.

GRÖNROOS, C. Service Management and Marketing. Lexington: Lexington Books, 2004.

HICKEY, K.; LAKE, N. The Customer Service Handbook. Burlington: Butterworth-Heineman, 2003. 
JOHNSTON, R.; CLARK, G. Administração de Operações de Serviço. São Paulo: Atlas, 2002.

KAUFMANN, F. Metodologia das Ciências Sociais. Rio de Janeiro: Francisco Alves, 1977.

KOTTER, J. P. Leading Change. Boston: Harvard University Press, 1996.

LAWLER, E. E. Organizing for High Performance. New York: John Wiley Trade, 2001.

LELAND, K. ; BAILEY, K. Customer Service for Dummies. Ontario: Wiley, 2006.

MADRUGA, R. P. Gestão Moderna de Call Center/ Telemarketing. São Paulo: Atlas, 2006.

MARCONI, M. A.; LAKATOS, E. M. Técnicas de Pesquisa. São Paulo: Atlas, 1990.

MITCHELL, A. The End of the Hype. Marketing Business, New York, Nov., 2001.

MORESI, E. A. D. Inteligência Organizacional. Ciência da Informação, Brasília, v. 29, 2001.

MUDIE, P.; PIRRIE, A. Services Marketing Management. London: Elsevier, 2006.

NONAKA, I. The Knowledge Creating Company. Harvard Business Review, Massachusetts, Nov./Dec., 1991.

POPPER, K. S. A Lógica da Pesquisa Científica. São Paulo: Cultrix, 1975a.

Conhecimento Objetivo. São Paulo: Cultrix, $1975 b$.

PORTNY, S. E. Project Management for Dummies. Ontario: Wiley, 2001.

PROBST, G.; RAUB, S.; ROMHARDT, K. Gestão do Conhecimento. Porto Alegre: Bookman, 2002.

READ, B. B. Designing the Best Call Center for your Business. New York: CMP Books, 2005.

SHARP, D. Call Center Operation. Burlington: Butterworth-Heineman, 2003.

SKYRME, D. J. Knowledge Networking. London: Butterworth Heinemann, 1999.

SPECTOR, R. The Nordstrom Way to Customer Service Excellence. New York: John Wiley Trade, 2005.

SVEIBY, K. E. The New Organizational Wealth. Sydney: BerrettKoehler, 1998.

THIOLLENT, M. Pesquisa-Ação nas Organizações. São Paulo: Atlas, 1997.

VERGARA, S.C. Projetos e Relatórios de Pesquisa em Administração. São Paulo: Atlas, 1998.

; BRANCO, P. D. Empresa Humanizada. RAE, São Paulo, v. 41, 2001.

ZEITHAML, V. A.; BITNER, M. J. Marketing de Serviços. Porto Alegre: Bookman, 2003. 


\section{Dados dos autores}

Nome completo: Samuel Ribeiro Tavares

Filiação institucional: Universidade Metodista de Piracicaba - UNIMEP

Departamento: Programa de Pós-graduação em Engenharia de Produção

Função ou cargo ocupado: Pesquisador

Endereço completo para correspondência (bairro, cidade, estado, país e CEP): Rua Alzira Peres

Xavier, 92. Quitaúna, Osasco - SP. CEP 06182-220

Telefones para contato: 01136080110

e-mail: samueltavares@yahoo.com

Nome completo: Milton Vieira Junior

Filiação institucional: Universidade Nove de Julho - UNINOVE

Departamento: Programa de Pós-graduação em Engenharia de Produção

Função ou cargo ocupado: Professor / Pesquisador

Endereço completo para correspondência (bairro, cidade, estado, país e CEP): Avenida Francisco

Matarazzo, 612. Água Branca, São Paulo - SP. CEP 05001-010

Telefones para contato: 01136659355

e-mail: mvieirajr@uninove.br 